\title{
PADI4 Haplotypes in Association with RA Mexican Patients, a New Prospect for Antigen Modulation
}

\author{
Maria Guadalupe Zavala-Cerna, ${ }^{1}$ Norma Guadalupe Gonzalez-Montoya, ${ }^{2}$ \\ Arnulfo Nava, ${ }^{1,2}$ Jorge I. Gamez-Nava, ${ }^{2}$ Maria Cristina Moran-Moguel, ${ }^{3}$ \\ Roberto Carlos Rosales-Gomez, ${ }^{3}$ Susan Andrea Gutierrez-Rubio, ${ }^{3}$ Jose Sanchez-Corona, ${ }^{3}$ \\ Laura Gonzalez-Lopez, ${ }^{4}$ Ingrid Patricia Davalos-Rodriguez, ${ }^{5}$ and Mario Salazar-Paramo ${ }^{6}$ \\ ${ }^{1}$ Programa Internacional del ICB, Facultad de Medicina, Universidad Autónoma de Guadalajara, Guadalajara, JAL, Mexico \\ ${ }^{2}$ Unidad de Investigación en Epidemiología Clínica, Hospital de Especialidades, Centro Médico Nacional de Occidente del \\ Instituto Mexicano del Seguro Social, Guadalajara, JAL, Mexico \\ ${ }^{3}$ División de Medicina Molecular del Centro de Investigación Biomédica de Occidente, Instituto Mexicano del Seguro Social, \\ Guadalajara, JAL, Mexico \\ ${ }^{4}$ Departamento de Medicina Interna-Reumatología del Hospital General Regional No. 110, Instituto Mexicano del Seguro Social, \\ Guadalajara, JAL, Mexico \\ ${ }^{5}$ División de Genética, CIBO, IMSS and Instituto de Genética Humana, CUCS Universidad de Guadalajara, Guadalajara, JAL, Mexico \\ ${ }^{6}$ División de Investigación en Salud, UMAE, Hospital de Especialidades, CMNO, IMSS and Departamento de Fisiología, CUCS, \\ Universidad de Guadalajara, Mexico
}

Correspondence should be addressed to Mario Salazar-Paramo; msalazpa@terra.com.mx

Received 31 May 2013; Revised 5 September 2013; Accepted 23 September 2013

Academic Editor: Timothy B. Niewold

Copyright (C) 2013 Maria Guadalupe Zavala-Cerna et al. This is an open access article distributed under the Creative Commons Attribution License, which permits unrestricted use, distribution, and reproduction in any medium, provided the original work is properly cited.

Peptidyl arginine deiminase IV (PAD 4) is the responsible enzyme for a posttranslational modification called citrullination, originating the antigenic determinant recognized by anti-cyclic citrullinated peptide antibodies (ACPA). Four SNPs (single nucleotide polymorphisms) have been described in PADI4 gene to form a susceptibility haplotype for rheumatoid arthritis (RA); nevertheless, results in association studies appear contradictory in different populations. The aim of the study was to analyze if the presence of three SNPs in PADI4 gene susceptibility haplotype (GTG) is associated with ACPA positivity in patients with RA. This was a cross-sectional study that included 86 RA patients and 98 healthy controls. Polymorphisms PADI4_89, PADI4_90, and PADI4_92 in the PADI4 gene were genotyped. The susceptibility haplotype (GTG) was more frequent in RA patients; interestingly, we found a new haplotype associated with RA with a higher frequency (GTC). There were no associations between polymorphisms and high scores in Spanish HAQ-DI and DAS-28, but we did find an association between RARBIS index and PADI4_89, PADI4_90 polymorphisms. We could not confirm an association between susceptibility haplotype presence and ACPA positivity. Further evidence about proteomic expression of this gene will determine its participation in antigenic generation and autoimmunity.

\section{Introduction}

Rheumatoid arthritis (RA) is an autoimmune disease, characterized by articular inflammation which can lead to joint destruction. RA prevalence is $1 \%$ worldwide with considerable variation between ethnic groups, with a higher prevalence in Caucasians compared with Asiatic populations [1,2]. This disease is more frequent in females $(3: 1)$ around the fourth decade [3]; some studies suggest that sexual hormones, specifically estrogens, can cause hyperactivity in B and T cell functions [4]. RA represents a disease with risk of function disability due to articular damage as a result of ongoing inflammation, which is irretrievable. In order to limit illness incapability, it is necessary to establish the diagnostic as soon as possible and treat the condition.

Genetic predisposition for this disease is supported by the following findings: (1) first degree relatives of patients 
with RA have a four to six times greater risk to develop the disease [5]; (2) presence of some HLA-DR molecules (HLA$\mathrm{DRB1}^{*} 0401$ and HLA-DRB1* 0404$)$ are genetic factors commonly found in RA, and its presence is associated with a more severe disease $[6,7]$. The epidemiological genetic information suggests that the heritability for this disease ranges between 53 and 60\%. Linkage disequilibrium studies revealed susceptibility loci for RA located within several chromosomes, one consistently implicated is the HLA-DRB1 gene [8]. Since this locus represents approximately one third of the total genetic effect, other loci should be considered to be part of RA development.

The peptidyl arginine deiminase IV gene denominated PADI4, located in 1p36.13, was recently acknowledged as one in association with RA, mainly in Japanese populations [9]. Suzuki and cols. described 17 single nucleotide polymorphisms (SNPs), four of them located in gene coding regions (exons 2-4). They found five haplotypes differing in four polymorphic sites; one denominated the susceptibility haplotype and was associated with RA. The SNPs involved are named PADI4_89, PADI4_90, PADI4_92, and PADI4_104; the first three determine an amino acid change, and the last one is a silent polymorphism [9-11]. In this same study, Suzuki and cols. described that this functional haplotype affected transcript stability, decreasing its degradation four times, and also demonstrated an association between haplotype homozygous individuals and ACPA positivity in patients with RA. In another study, this increase in PADI4 mRNA stability was confirmed when mononuclear cells of peripheral blood from patients with RA were analyzed [12].

The protein peptidylarginine deiminase (PAD 4) consists of 663 amino acid residues with a $74 \mathrm{kDa}$ molecular weight [13] and is the only isotype out of five described to be expressed in cell nucleus [14]. PAD enzymes have diverse physiologic functions including aggregation of keratin during terminal differentiation in the epidermis [15], involvement in brain development [16], and gene expression regulation by chromatin modeling $[14,17]$. PAD 4 enzyme is responsible for a posttranslational modification called citrullination, originating the antigenic determinant recognized by anti-cyclic citrullinated peptide antibodies (ACPA). PAD 4 is a calcium dependant enzyme, an increase in cytosolic $\mathrm{Ca}^{+2}$ concentration $(2 \mu \mathrm{M})$ is needed for citrullinated antigens to appear [13]. Since calcium ions induce conformational changes that create the active site in the $\alpha / \beta$ catalytic domain of the enzyme. Intracellular calcium concentrations range from $200 \mathrm{nM}$ (resting cells) to $\sim 1 \mu \mathrm{M}$ (activated cells) [18], and calcium concentrations in the cytosol can be increased during apoptosis or necrosis, leading to PAD activation and protein citrullination $[19,20]$. Consequences of protein citrullination include protein charge neutralization, change in isoelectric point, ionic interaction breakage, partial protein unfolding, decrease in photolytic degradation, increase in antigenicity, and affinity changes with HLA.

Our interest in the present study comes after the discovery of ACPA, since not only have they shown high sensitivity (80\%) and specificity (98\%) [21], but they have also demonstrated a positive predictive value [22] in healthy blood donors who developed RA over the years [23] and in patients with undifferentiated arthritis [24]. Several authors have suggested that protein citrullination and autoantibody production are two processes implicated in RA development $[24,25]$, and nevertheless, the exact mechanism has not been elucidated.

One theory involves the possibility that susceptibility haplotype presence may induce an increase in transcript stability, which would lead to an elevated PAD 4 level and as a consequence citrullination of more epitopes that would break tolerance and induce production of autoantibodies against citrullinated peptides, thus initiating an autoimmune response.

Although evidence exists supporting the presence of PADI4 susceptibility haplotype in RA Japanese patients [9] and Taiwan patients [26], it could not be extrapolated to other populations [27-29], and it is important to repeat association studies in populations with different ethnic background, in order to find and replicate previous findings related to PADI4 susceptibility haplotype. The purpose of the present study was to analyze if the presence of three SNPs in PADI4 gene susceptibility haplotype (GTG) is associated with ACPA positivity in Mexican patients with RA.

\section{Material and Methods}

2.1. Patients and Samples. We carried out a cross-sectional study that included 86 patients and 98 healthy subjects from northwestern Mexico who attended to the rheumatology outpatient clinical facilities at "Instituto Mexicano del Seguro Social" in Guadalajara, JAL, Mexico. All patients were classified as RA according to the 1987 ACR classification criteria [30] and fulfilled other inclusion criteria: voluntary acceptance to participate in the study and being able to answer questionnaires. We only included patients with Mestizo ethnicity since two previous generations; patients were not related to each other. Clinical data was obtained from direct interrogatory and physical examination, as well as a chart review in order to identify clinical variables such as disease duration, characteristics of the disease, and therapeutics. Two rheumatologists systematically evaluated the following indexes: DAS-28 [31] to establish severity of disease activity and Spanish HAQ-DI [32] to determine patient disability. We also obtained information from clinical charts in order to evaluate the RARBIS [33] that constitutes a medical recordsbased index to evaluate RA severity. Patients were included in any functional class according to Steinbrocker Functional Classification, and all of them were receiving treatment; these data was recorded.

Exclusion criteria included patients who had a diagnosis of other rheumatic disease, inability to access patient clinical chart, insufficient amount of sample, or bad quality DNA after extraction.

Healthy controls were blood donors who attended to "Instituto Mexicano del Seguro Social” blood bank and denied having any chronic disease.

2.2. Genotyping. DNA from 86 patients with rheumatoid arthritis and 98 healthy subjects was extracted from blood 
TABLE 1: Genotyping strategies for PADI4 polymorphism variants detection.

\begin{tabular}{|c|c|c|c|c|c|c|}
\hline SNP & Primers & $T_{m}\left({ }^{\circ} \mathrm{C}\right)$ & $\begin{array}{l}\text { Band size } \\
\text { (bp) }\end{array}$ & $\begin{array}{l}\text { Restriction } \\
\text { enzyme }\end{array}$ & $\begin{array}{l}\text { Recognized } \\
\text { sequence }\end{array}$ & $\begin{array}{l}\text { Band size after digestion } \\
\text { (bp) }\end{array}$ \\
\hline PADI4_89 & $\begin{array}{l}5^{\prime} \text {-TCTGCTTTCCCATGTGTCTTG-3' } \\
5^{\prime} \text {-AGGACAGAGTGTGTGTGGCTG-3' }\end{array}$ & 61 & 278 & HaeIII & GGCC & $\begin{array}{l}\text { G } 100,95,43, \text { and } 40 \\
\text { A } 140,95, \text { and } 43\end{array}$ \\
\hline PADI4_90 & $\begin{array}{l}5^{\prime} \text {-AAATCCACAGGTTCCTCCACA-3' } \\
5^{\prime} \text {-CATCACGAGCTCTTCCACAGG-3' }\end{array}$ & 62 & 221 & $M s c I$ & TGGCA & $\begin{array}{l}\text { T } 154 \text { and } 67 \\
\text { C } 221\end{array}$ \\
\hline PADI4_92 & $\begin{array}{l}5^{\prime} \text {-CCCAACTTTGTCTCCCCAGT-3' } \\
5^{\prime} \text {-TTGTGGTTCACTGACTAAGGAT-3' }\end{array}$ & 61 & 363 & $M s p I$ & CCGG & $\begin{array}{l}\text { G } 195,134 \text {, and } 34 \\
\text { C } 329 \text { and } 34\end{array}$ \\
\hline
\end{tabular}

SNP: single nucleotide polymorphism, $T_{m}$ : fusion mean temperature, and bp: base pair.

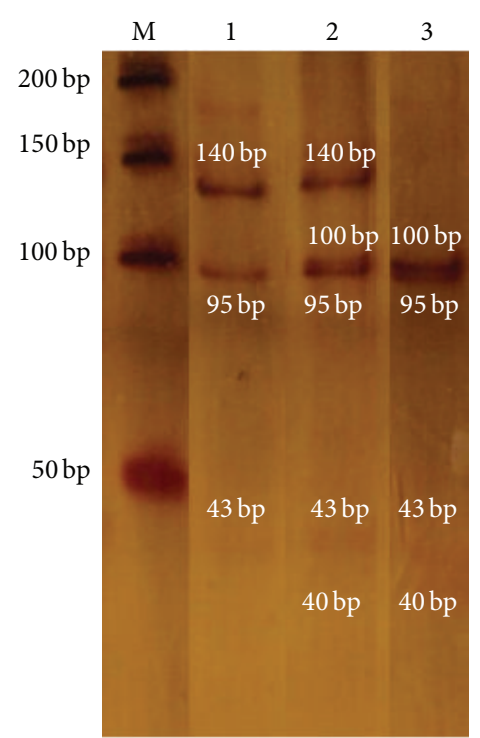

(a)

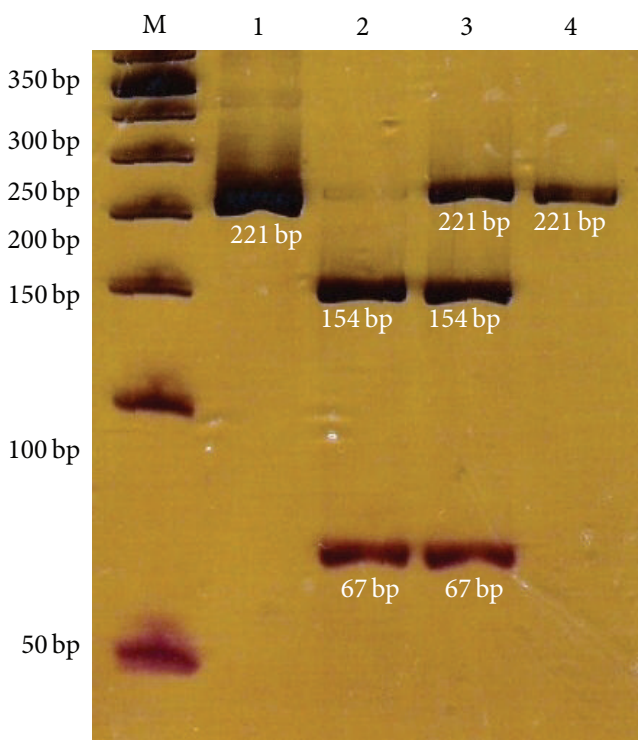

(b)

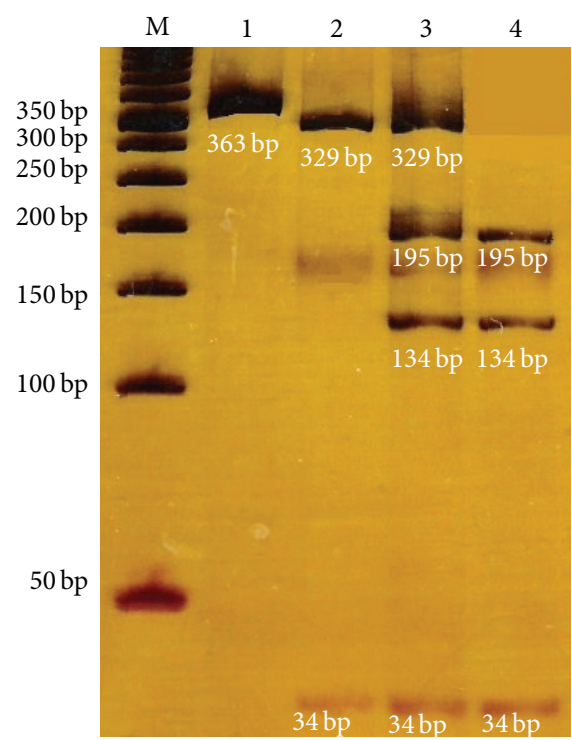

(c)

Figure 1: PADI4 SNPs enzyme digestion. The figure shows digestion of three SNPs in the PADI4 gene. (a) Shows digestion of PADI4_89, with HaeIII enzyme; lane 1 represents the A/A genotype, lane 2 A/G and 3 G/G. (b) Demonstrates PADI4_90 amplification (221 bp) in lane 1 and digested products with $\mathrm{MscI}$ enzyme in lanes 2 (C/C genotype), 3 (C/T genotype), and 4 (T/T genotype). (c) Shows amplification product of PADI4_92 in lane 1 (363 bp) and restriction products obtained with the enzyme MspI; lane 2 corresponds to the G/G genotype, lane 3 G/C, and lane $4 \mathrm{C} / \mathrm{C}$. Visualized in $8 \%(29: 1)$ polyacrylamide gel with silver staining. M: molecular weight marker (50 bp).

samples using conventional methods [34] and stored frozen at $-80^{\circ} \mathrm{C}$.

Genotyping for polymorphisms PADI4_89, PADI4_90, and PADI4_92 in the PADI4 gene was determined by three polymerase chain reaction-restriction fragment length polymorphisms (PCR_RFLPs) protocols designed using Oligo 0.4 software, BLAST, and NEBcutter V.2.0. Table 1 shows primer sequence and obtained products. Each PCR reaction was carried out in $10 \mu \mathrm{L}$ final volume containing (final concentrations): $1 \mathrm{X}$ buffer (200 mM Tris- $\mathrm{HCl} \mathrm{pH} \mathrm{8.4,} 500 \mathrm{mM}$ $\mathrm{KCl}$, and $4 \mathrm{mM} \mathrm{MgCl}$ ); $5 \mathrm{pmol} / \mathrm{mL}$ each of the pair primers according to polymorphism (Table 1 ); $10 \mathrm{mM}$ each of the four deoxyribonucleoside triphosphates; $1 \mathrm{U}$ of taq DNA polymerase (Invitrogen, Carslbad, CA, USA); and 200 to 300 ng DNA template. The PCR products were visualized by electrophoresis in $8 \%(29: 1)$ polyacrylamide gels at $150 \mathrm{~V}$ for $1 \mathrm{~h}$, followed by silver staining. The PADI4_89, PADI4_90, and PADI4_92 genotypes were identified after restriction enzyme digestion with HaeIII, MscI, and MspI, respectively (New England Biolabs, MS, USA), shown in Figure 1.
2.3. Haplotypes. Haplotype analysis was done using the software PHASE v 1.0 for haplotype reconstruction, and recombination rate estimation was done using the genotypic data [35].

2.4. Anti-Cyclic Citrullinated Peptide (ACPA) Antibody Assay. ACPA (IgG) was measured using a commercially available second generation enzyme-linked immunosorbent assay (ELISA-II), according to the manufacturer instructions (EUROIMMUN, UK). Briefly, test samples, calibrator, and controls are incubated in the respective wells, containing the citrullinated peptide. Antibodies will bind, and nonbound material is removed by washing. Next, peroxidase conjugated anti-human IgG is added to each well. After incubation with substrate solution, the reaction is stopped, and density values were obtained with a spectrophotometer at a wave length of 405/620 nm. Results were expressed in relative units per milliliter $(\mathrm{RU} / \mathrm{mL})$, considering positive when the result was $>5 \mathrm{RU} / \mathrm{mL}$. 
TABle 2: Demographic and clinical characteristics of RA patients.

\begin{tabular}{lc}
\hline Characteristic & RA $(n=86)$ \\
\hline Age $(x \pm$ SD) & $50 \pm 12$ \\
Smoking & $17 \%$ \\
Years with RA $(x \pm$ SD) & $11 \pm 7$ \\
Functional class & \\
I & $8 \%$ \\
II & $79 \%$ \\
III & $11 \%$ \\
IV & $2 \%$ \\
HAQ-DI $(x \pm$ SD) & $1.22 \pm 1.00$ \\
DAS 28 $(x \pm$ SD) & $4.4 \pm 1.3$ \\
RARBIS $(x \pm$ SD) & $6.26 \pm 2.70$ \\
RF (IgG) + & $66 \%$ \\
ACPA (IgM) + & $74 \%$ \\
Treatments & $n(\%)$ \\
Chloroquine & $33(38)$ \\
Sulfasalazine & $47(55)$ \\
Methotrexate & $65(76)$ \\
Azathioprine & $25(29)$ \\
Cyclosporine & $1(1)$ \\
Infliximab & $2(2)$ \\
Etanercept & $10(11)$ \\
Cyclophosphamide & $1(1)$ \\
Corticosteroids & $72(80)$ \\
\hline
\end{tabular}

HAQ-DI: health assessment questionnaire disability index, DAS: disease activity score, RARBIS: RA medical records-based index of severity, and RF: rheumatoid factor.

2.5. Statistical Analysis. Allelic and genotypic frequencies were determined by gene count. Comparisons between groups for nominal and categorical variables were performed by applying chi square test or Fisher exact test as indicated. A $P$ value of $\leq 0.05$ was considered significant. Hardy-Weinberg equilibrium was tested.

\section{Results}

3.1. Demographics and Clinical. We included 89 patients; all of them attended to rheumatology clinic and were classified as RA according to ACR classification criteria [30]. Three of them were excluded because of poor DNA quality. Mean age was $50 \pm 12$ years, $100 \%$ of the studied subjects were women, mean duration disease was $11 \pm 7$, years and all of them were receiving treatment, some of them with monotherapy and others combined therapy, and the number and percentages of patients taking a specific drug are listed in Table 2. Results from HAQ-DI, DAS-28, and RARBIS are also shown in Table 2.

3.2. Molecular Analysis. In this comparative study of 86 patients and 98 controls, we found a significant association between three exonic SNPs of PADI4 gene and RA $(P<$ 0.05). Genotypic and allelic frequencies are listed on Table 3 confirming previous association studies.
Carriage of PADI4_89 G allele (OR 2.51, 95\% CI 1.195.32) and PADI4_90 T allele (OR 2.64 95\% CI 1.21-5.75) was associated with susceptibility to RA. The PADI4_92 G allele could not be associated with RA (OR 2.08, 95\% CI 0.81-5.36).

The three nonsynonymous polymorphisms PADI4_89 (163G/A), PADI4_90 (245T/C), and PADI4_92 (335G/C) constituted mainly eight haplotypes; their sequence and frequencies are represented in Table 4 . We found significant association $(P<0.0005)$ of the susceptibility haplotype (Haplotype 1) and RA condition with an OR (95\% CI) of 19 (2.4 to 147), and this haplotype was present in 14 patients with $\mathrm{RA}$ and only one control. Interestingly, another haplotype was associated significantly with RA (Haplotype 3); this haplotype was present in a higher frequency: 42 patients and 28 controls $(P=0.006)$ OR $(95 \% \mathrm{CI})=2.4(1.3-4.4)$. The nonsusceptibility haplotype (Haplotype 2 ) did not display significant differences.

3.3. Antibodies against Cyclic Citrullinated Peptide (ACPA) ( $\operatorname{Ig} G$ ). From 86 patients with RA, 74\% had ACPA positivity, and mean $\pm \mathrm{SD}$ was $5.98 \pm 4.15 \mathrm{RU} / \mathrm{mL}$. We did not find an association between ACPA positivity and the presence of genetic variants in PADI4_89, PADI4_90, and PADI4_92 polymorphisms of PADI4 gene; results are shown in Figure 2. We neither found an association between high titers of ACPA and risk allele (data not shown in graph). Fifteen patients had positive smoking, and we searched antibody positivity among them and found eight positive cases with mean \pm SD titers of $8.41 \pm 2.98 \mathrm{RU} / \mathrm{mL}$.

3.4. Clinical Data and PADI4 Gene Polymorphisms. We searched for possible associations between clinical data, high punctuation score of HAQ-DI DAS-28 and RARBIS indexes with susceptibility haplotype, or the presence of polymorphisms PADI4_89, PADI4_90, and PADI4_92 of PADI4 gene in RA patients. The only clinical variable significantly associated was the presence of high score in RARBIS index with $G$ allele (susceptibility) of PADI4_89 SNP $(P=0.007)$ and with T/T genotype (homozygous susceptible) of PADI4_90 $(P=0.04)$. For PADI4_92, we did not find any significant association $(P=0.84)$ (data not shown in tables).

\section{Discussion and Conclusion}

During the last decade, RA pathogenesis research has been centered in the idea that multiple cells and molecular mechanisms of the immune system are involved; nevertheless, from this complicated view, a common point emerges: escape from immunological control leading to loss of tolerance with lymphocyte $\mathrm{T}$ activation and $\mathrm{B}$ cells production of autoantibodies [36]. The self/nonself theory of the immune system fails to explain how autoimmune responses are being generated, since our immune system should be tolerant to self molecules. Matzinger [37] proposed an alternative model that suggested, in addition to antigen presentation, the presence of danger signals that are released after tissue injury and can trigger immune responses [38, 39]. First observations of the relationship between cellular lyses and inflammation go back to inflammasome description; produced spontaneously after 
TABLE 3: Genotypic and allelic frequencies of PADI4_89, PADI4_90, and PADI4_92 SNPs of PADI4 gene in controls (HC $n=98)$ and rheumatoid arthritis (RA $n=86)$ patients.

\begin{tabular}{|c|c|c|c|c|c|c|c|c|}
\hline SNPs & Genotypes & RA & $\mathrm{HC}$ & Allele & RA & $\mathrm{HC}$ & $P$ & OR (95\% CI) \\
\hline \multirow{3}{*}{ PADI4_89 } & $\mathrm{A} / \mathrm{A}$ & 0.148 & 0.305 & $\mathrm{~A}$ & 0.488 & 0.581 & \multirow{3}{*}{0.040} & \multirow{3}{*}{$2.51(1.19-5.32)$} \\
\hline & $\mathrm{A} / \mathrm{G}$ & 0.679 & 0.551 & G & 0.512 & 0.419 & & \\
\hline & $\mathrm{G} / \mathrm{G}$ & 0.173 & 0.144 & & & & & \\
\hline \multirow{3}{*}{ PADI4_90 } & $\mathrm{C} / \mathrm{C}$ & 0.136 & 0.278 & $\mathrm{C}$ & 0.420 & 0.562 & \multirow{3}{*}{0.004} & \multirow{3}{*}{$2.64(1.21-5.75)$} \\
\hline & $\mathrm{C} / \mathrm{T}$ & 0.568 & 0.567 & $\mathrm{~T}$ & 0.580 & 0.438 & & \\
\hline & $\mathrm{T} / \mathrm{T}$ & 0.296 & 0.155 & & & & & \\
\hline \multirow{3}{*}{ PADI4_92 } & $\mathrm{C} / \mathrm{C}$ & 0.086 & 0.165 & $\mathrm{C}$ & 0.438 & 0.454 & \multirow{3}{*}{0.732} & \multirow{3}{*}{$2.08(0.81-5.36)$} \\
\hline & $\mathrm{C} / \mathrm{G}$ & 0.704 & 0.578 & G & 0.562 & 0.546 & & \\
\hline & $\mathrm{G} / \mathrm{G}$ & 0.210 & 0.257 & & & & & \\
\hline
\end{tabular}

SNP: single nucleotide polymorphism, HC: healthy controls, RA: rheumatoid arthritis, OR: odds ratio, and 95\% CI: 95\% confidence interval.

In order to compute OR (95\% CI), the following alleles were used as reference: PADI4_89 allele A, PADI4_90 allele C, and PADI4_92 allele C in correspondence with the nonsusceptibility haplotype (ACC).

TABLE 4: Haplotype sequence and frequency of PADI4 gene SNPs (PADI4_89, PADI4_90, and PADI4_92) in healthy controls and RA patients.

\begin{tabular}{|c|c|c|c|c|c|}
\hline \multirow{2}{*}{ Haplotypes } & \multirow{2}{*}{ Condition } & \multicolumn{2}{|c|}{ Frequencies } & \multirow{2}{*}{$P$} & \multirow{2}{*}{ OR (95\% CI) } \\
\hline & & $\mathrm{RA}(n=86)$ & $\mathrm{HC}(n=98)$ & & \\
\hline \multirow{2}{*}{ Haplotype 1 susceptibility GTG } & Present & 14 & 1 & \multirow{2}{*}{0.0002} & \multirow{2}{*}{$18.9(2.4-146.8)$} \\
\hline & Absent & 72 & 97 & & \\
\hline \multirow{2}{*}{ Haplotype 2 nonsusceptibility ACC } & Present & 5 & 6 & \multirow{2}{*}{1} & \multirow{2}{*}{$0.95(0.3-3.2)$} \\
\hline & Absent & 81 & 92 & & \\
\hline \multirow{2}{*}{ Haplotype 3 new susceptibility GTC } & Present & 42 & 28 & \multirow{2}{*}{0.006} & \multirow{2}{*}{$2.4(1.3-4.4)$} \\
\hline & Absent & 44 & 70 & & \\
\hline \multirow{2}{*}{ Haplotype 4 ACG } & Present & 43 & 39 & \multirow{2}{*}{0.18} & \multirow{2}{*}{$1.5(0.8-2.7)$} \\
\hline & Absent & 43 & 59 & & \\
\hline \multirow{2}{*}{ Haplotype 5 GCG } & Present & 1 & 10 & \multirow{2}{*}{0.011} & \multirow{2}{*}{$0.1(0.01-0.8)$} \\
\hline & Absent & 85 & 88 & & \\
\hline \multirow{2}{*}{ Haplotype 6 ATC } & Present & 3 & 8 & \multirow{2}{*}{0.22} & \multirow{2}{*}{$0.4(0.1-1.6)$} \\
\hline & Absent & 83 & 90 & & \\
\hline \multirow{2}{*}{ Haplotype 7 ATG } & Present & 6 & 6 & \multirow{2}{*}{1} & \multirow{2}{*}{$1.1(0.4-3.7)$} \\
\hline & Absent & 81 & 92 & & \\
\hline \multirow{2}{*}{ Haplotype 8 GCC } & Present & 1 & 4 & \multirow{2}{*}{0.4} & \multirow{2}{*}{$0.3(0.03-2.5)$} \\
\hline & Absent & 85 & 94 & & \\
\hline
\end{tabular}

HC: healthy controls, RA: rheumatoid arthritis, and SNPs: single nucleotide polymorphisms.

cellular membrane disruption [40], inflammasome activation causes the release of IL-1 $\beta$, IL-18, and IL-33 cytokines, which can activate $\mathrm{B}$ and $\mathrm{T}$ lymphocytes and contribute to the development of inflammatory and autoimmune diseases [41].

Over the years, several paradigms have been broken with respect to RA pathogenesis. In 1997, Weyand and Goronzy [42] proposed a new hypothetical model; this model integrates genetic risk factors to immune inflammatory responses [42]. PADI4 susceptibility haplotype could be a genetic risk factor, but before PADI4 gene polymorphisms are considered genetic markers for RA, it was mandatory to replicate the association findings first reported in Asiatic populations; nevertheless, such findings could not be replicated in other populations (Table 5) $[27,28]$. In the last years, two metaanalyses have been published pretending to clarify the existence of a true association in different populations $[43,44]$, since such studies can increase sample size and precision, thus reducing the probability of incising in false positive or false negative results. In Lee and colleagues. study, three Asiatic and six European populations were included [44]; a significant association between RA and PADI4 polymorphisms was found (PADI4_94, PADI4_104, and PADI4_90).

The present study represents the first one in Mexican population which is the result of genetic admixture of Spanish, Indian, and Black populations, and it should be emphasized that the genetic background introduced from Spaniards includes genes from Romans, Greeks, Visigods, Arabs, and Jews [45]. We should point out that three new PCR-RFLP protocols were designed for the conduction of the present study; we pretend that this approach of association can be replicated in laboratories where equipment for DNA sequencing or RT-PCR is not available, since these have been methodologies described in previous reports $[9,46]$. 


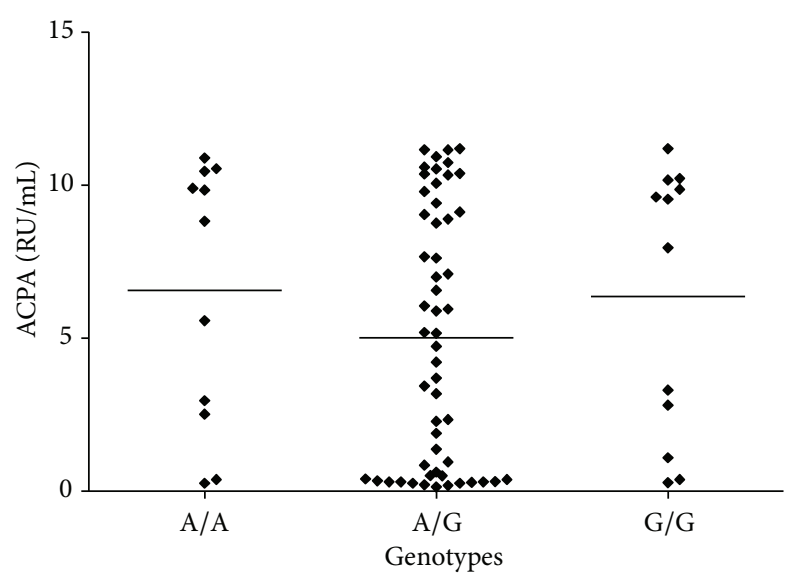

(a)

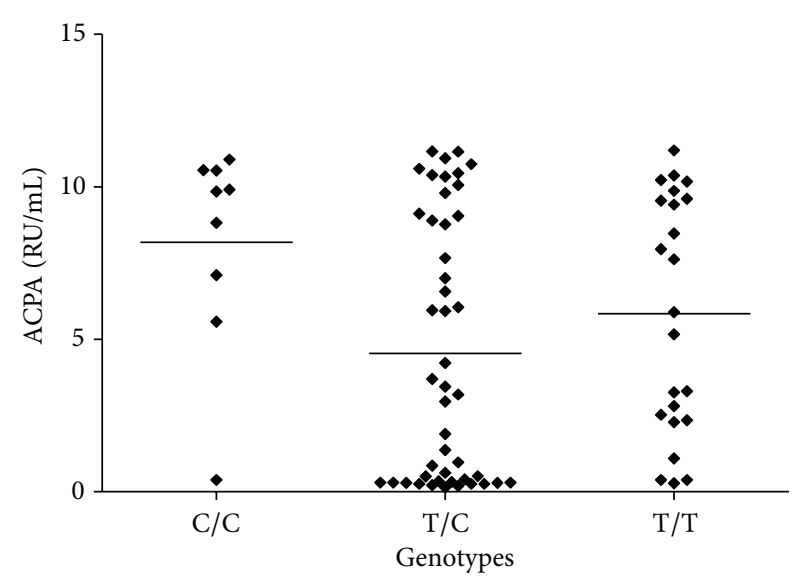

(b)

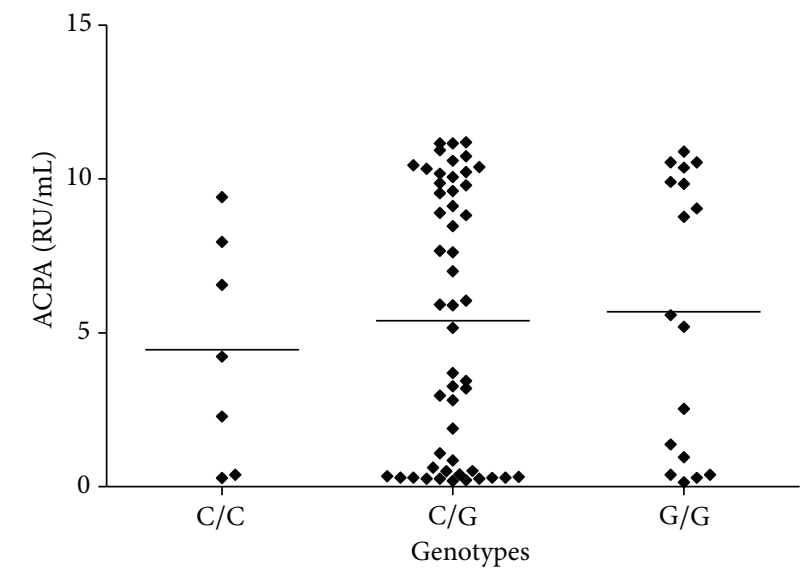

(c)

FIGURE 2: Anti-cyclic citrullinated peptide antibodies (ACPA) titers in the presence of genetic variants in PADI4_89, PADI4_90, and PADI4_92 polymorphisms of PADI4 gene.

We found that PADI4 polymorphisms are associated with RA susceptibility, regardless of ACPA titers. This is consistent with results published by Hoppe and Kang et al. in German [11] and Korean [47] populations, respectively. Our findings also show partial concordance with results in Japanese population [9], since PADI4_89 and PADI4_90 were associated with RA in our study. A recent meta-analysis [44] concluded that PADI4 gene polymorphisms could have a higher susceptibility role in Asiatic populations compared to Caucasians, but soon after that, an association between PADI4 gene and RA was confirmed in a French population [48]. The lack of replication in different studies could be attributed to (1) false positive results in the primary report due to sample bias, (2) false negative in the replication study due to lack of statistical power, or (3) true genetic heterogeneity exists.

When we analyzed haplotype frequencies, we found that the susceptibility haplotype (GTG) was significantly associated with RA $(P=0.0002)$, but more interestingly, we found a new haplotype (GTC) which was both significantly associated $(P=0.006)$ and more frequent than previous susceptibility haplotype. We believe that since this second haplotype was present in a higher frequency among RA patients, it should be looked forward.
In the present study, our patients with RA had an active disease according to DAS 28 and a significant limitation in functioning according to HAQ-DI. Nevertheless, an exploratory subanalysis did not observe a significant association between the presence of polymorphisms PADI4_89, PADI4_90, and PADI4_92 of PADI4 gene with high scores in DAS 28 or HAQ-DI. Instead, a G allele of PADI4_89 SNP and T/T genotype of PADI4_90 were significantly associated with higher score in RARBIS. The RARBIS index is based on patient records and could represent a confident tool to measure disease severity, but it is not yet validated in Spanish. It would be desirable that other association studies could further characterize their population with the use of these clinical scores, since most of the association studies do not present clinical data. Furthermore, a deficient clinical characterization of the group of study could contribute to inconsistencies in results.

In our RA patient group, ACPA (IgG) positivity was present in $74 \%$, similar to previous reports $[44,49,50]$. We did not find an association between polymorphisms or haplotype susceptibility of the PADI4 gene and positivity or elevated titers of ACPA. It should be noted that previous association between ACPA positivity and susceptibility haplotype was described in homozygous subjects to the susceptibility 
TABLE 5: Association studies for PADI4 SNPs and rheumatoid arthritis.

\begin{tabular}{|c|c|c|c|}
\hline SNPs & $\begin{array}{l}\text { Country } \\
\text { RA/HC }\end{array}$ & Results & Reference \\
\hline PADI4_89-105 & $\begin{array}{c}\text { Japan } \\
(830 / 736)\end{array}$ & $\begin{array}{c}\text { PADI4_92, 94, 95, 97, 99, 100, } 101 \text { and } 104 \\
(P=0.0000084-0.00051)\end{array}$ & Suzuki et al. 2003 [9] \\
\hline PADI4_89, 90, 92, 104 & $\begin{array}{c}\text { UK } \\
(839 / 481)\end{array}$ & $\begin{array}{l}\text { Susceptibility haplotype more frequent in RA } \\
\text { patients (32.3 versus 29.6) without significance } \\
\qquad(P=0.79)\end{array}$ & Barton et al. 2004 [27] \\
\hline PADI4_92, 96 and 102 & $\begin{array}{l}\text { France } \\
\text { (100 families) }\end{array}$ & No significant associations & Caponi et al. 2005 [28] \\
\hline $\begin{array}{l}\text { PADI4_92, 94, 97, 99, } \\
100,103 \text { and } 104\end{array}$ & $\begin{array}{l}\text { England } \\
(111 / 111)\end{array}$ & $\begin{array}{c}\text { PADI4_100 and } 103(P=0.03) \text {. Increase in } \\
\text { mRNA expression of } P A D I 4 \text { in PBM from RA } \\
\text { versus } C\end{array}$ & Harney et al. 2005 [12] \\
\hline PADI4_94, 102 and 104 & $\begin{array}{c}\text { Japan } \\
(1170 / 926)\end{array}$ & $\begin{array}{l}\text { PADI4_94, 102, and 104 } \\
\quad(P=0.0008-0.010)\end{array}$ & Ikari et al. 2005 [26] \\
\hline PADI4_94 and 104 & $\begin{array}{c}\text { Spain } \\
(354 / 498)\end{array}$ & No significant associations & Martinez et al. 2005 [29] \\
\hline PADI4_94 & $\begin{array}{l}\text { Sweden and North } \\
\text { America }\end{array}$ & $\begin{array}{l}\text { Association with RA } \\
\qquad(P=0.02)\end{array}$ & Plenge et al. 2005 [55] \\
\hline $\begin{array}{l}\text { PADI4_89, 90, } 92 \text { and } \\
104\end{array}$ & $\begin{array}{c}\text { Korea } \\
(545 / 392)\end{array}$ & $\begin{array}{l}\text { Strong association of RA with susceptibility } \\
\text { haplotype } \\
\left(P=1.0 \times 10^{-4}\right)\end{array}$ & Kang et al. 2006 [47] \\
\hline $\begin{array}{l}\text { PADI4_89, 90, 92, 94, 95, } \\
96 \text { and } 104\end{array}$ & $\begin{array}{l}\text { Germany } \\
(102 / 102)\end{array}$ & $\begin{array}{c}\text { PADI4_89, 90, and } 94 \\
(P=0.04)\end{array}$ & Hoppe et al. 2006 [11] \\
\hline PADI4_89 and 90 & $\begin{array}{c}\text { France } \\
(405 / 275)\end{array}$ & $\begin{array}{l}\text { Association with RA } \\
(P=0.03 \text { and } 0.003)\end{array}$ & Gandjbakhch et al. 2009 [48] \\
\hline
\end{tabular}

RA: rheumatoid arthritis, HC: healthy controls, and PBM: peripheral blood mononuclear.

haplotype according to Suzuki et al. [9] and Gandjbakhch et al. [48]. We did not find individuals who were homozygous for the susceptibility haplotype. Additionally, besides IgG isotype ACPA positivity, more recently, the presence of the IgM isotype was demonstrated at different times during the course of RA, indicating that ACPA production is a constant phenomenon during RA evolution [51] and seems to be an ongoing phenomena along disease duration [52]. For this reason, a lack of association between ACPA positivity and susceptibility haplotype presence in our study does not confirm that they are unrelated. Another important finding in ACPA research is the fact that citrullinated proteins can be found in synovium with inflammation caused by several pathologies [53], but the presence of ACPA remains specific for RA patients [10]. As a consequence, it has been suggested that ACPA could participate in RA generation, and there are two possible explanations for their development: the first one considers a high expression of citrullinated antigens which can originate loss of tolerance and as a result ACPA production contributing to inflammation and specific immune responses toward citrullinated antigens. The second theory postulates that RA patients have an abnormal humoral immune response towards citrullinated proteins and they start producing elevated amounts of antibodies against them.

Supporting the first theory is the fact that susceptibility haplotype presence can affect PADI4 translation, as the increase in mRNA stability has been demonstrated, generating an increase in protein levels and as a consequence a higher occurrence of citrullinated proteins [54]. Citrullination can contribute to the generation of antigens since it originates a change in amino acid charge (amine group is positively charged and citrulline is neutral). This may affect the tertiary or quaternary structure of the protein, allowing protein domains that where otherwise maintained in the internal protein structure to be exposed.

Finally, we did not find associations between PADI4 gene polymorphisms and clinical variables, except for high punctuation in RARBIS index and presence of susceptibility allele (G) in PADI4_89 or susceptibility homozygous (T/T) in PADI4_90 of PADI4 gene.

Limitations in this study include sample size since only one gender is represented in the present investigation; it is well known that RA is a condition that affects mainly women, but it would be desirable to increase sample size in order to be able to include male patients and to verify if association with the susceptibility haplotype remains constant, since in our study we were able to find only one $\mathrm{HC}$ with the susceptibility haplotype.

In conclusion, we confirm the association between the susceptibility haplotype (GTG) with RA patients, observing also that a new haplotype (GTC) could be associated with RA in Mexican mestizo patients. Further studies including other regions in Mexico and increasing the sample size are required in order to confirm our findings; furthermore, the biggest challenge for association studies is the identification of genetic variants that, combined in haplotypes, can be described as causal effects to RA. 


\section{Ethical Considerations}

This research was conducted in accordance with the Declaration of Helsinki. Informed consent was obtained from all participants, and the study protocol was approved by the Local Committees for Ethical and Health Research (CLIEIS 1301), and all data were managed anonymously.

\section{Acknowledgment}

This work was supported by Grant from CONACYT S00082007-1/69645 and FIS 2006/1A/I/067.

\section{References}

[1] A. M. Abdel-Nasser, J. J. Rasker, and H. A. Valkenburg, "Epidemiological and clinical aspects relating to the variability of rheumatoid arthritis," Seminars in Arthritis and Rheumatism, vol. 27, no. 2, pp. 123-140, 1997.

[2] Y. Alamanos and A. A. Drosos, "Epidemiology of adult rheumatoid arthritis," Autoimmunity Reviews, vol. 4, no. 3, pp. 130-136, 2005.

[3] G. S. Firestein, "Evolving concepts of rheumatoid arthritis," Nature, vol. 423, no. 6937, pp. 356-361, 2003.

[4] S. A. Ahmed, B. D. Hissong, D. Verthelyi, K. Donner, K. Becker, and E. Karpuzoglu-Sahin, "Gender and risk of autoimmune diseases: possible role of estrogenic compounds," Environmental Health Perspectives, vol. 107, supplement 5, pp. 681-686, 1999.

[5] R. M. Nakamura, "Progress in the use of biochemical and biological markers for evaluation of rheumatoid arthritis," Journal of Clinical Laboratory Analysis, vol. 14, no. 6, pp. 305313,2000 .

[6] D. L. Mattey, W. Thomson, W. E. R. Ollier et al., "Association of DRB1 shared epitope genotypes with early mortality in rheumatoid arthritis: results of eighteen years of followup from the early rheumatoid arthritis study," Arthritis and Rheumatism, vol. 56, no. 5, pp. 1408-1416, 2007.

[7] F. A. van Gaalen, J. van Aken, T. W. J. Huizinga et al., "Association between HLA class II genes and autoantibodies to Cyclic Citrullinated Peptides (CCPs) influences the severity of rheumatoid arthritis," Arthritis and Rheumatism, vol. 50, no. 7, pp. 2113-2121, 2004.

[8] C. M. Deighton, D. J. Walker, I. D. Griffiths, and D. F. Roberts, "The contribution of HLA to rheumatoid arthritis," Clinical Genetics, vol. 36, no. 3, pp. 178-182, 1989.

[9] A. Suzuki, R. Yamada, X. Chang et al., "Functional haplotypes of PADI4, encoding citrullinating enzyme peptidylarginine deiminase 4, are associated with rheumatoid arthritis," Nature Genetics, vol. 34, no. 4, pp. 395-402, 2003.

[10] E. R. Vossenaar, T. J. M. Smeets, M. C. Kraan, J. M. Raats, W. J. van Venrooij, and P. P. Tak, "The presence of citrullinated proteins is not specific for rheumatoid synovial tissue," Arthritis and Rheumatism, vol. 50, no. 11, pp. 3485-3494, 2004.

[11] B. Hoppe, T. Haupl, R. Gruber et al., "Detailed analysis of the variability of peptidylarginine deiminase type 4 in German patients with rheumatoid arthritis: a case-control study ", Arthritis Research \& Therapy, vol. 8, no. 2, article R34, 2006.

[12] S. M. J. Harney, C. Meisel, A.-M. Sims, P. Y. Woon, B. P. Wordsworth, and M. A. Brown, "Genetic and genomic studies of PADI4 in rheumatoid arthritis," Rheumatology, vol. 44, no. 7, pp. 869-872, 2005.
[13] Y. Luo, K. Arita, M. Bhatia et al., "Inhibitors and inactivators of protein arginine deiminase 4: functional and structural characterization," Biochemistry, vol. 45, no. 39, pp. 11727-11736, 2006.

[14] K. Nakashima, T. Hagiwara, and M. Yamada, "Nuclear localization of peptidylarginine deiminase $\mathrm{V}$ and histone deimination in granulocytes," Journal of Biological Chemistry, vol. 277, no. 51, pp. 49562-49568, 2002.

[15] T. Senshu, S. Kan, H. Ogawa, M. Manabe, and H. Asaga, "Preferential deimination of keratin $\mathrm{K} 1$ and filaggrin during the terminal differentiation of human epidermis," Biochemical and Biophysical Research Communications, vol. 225, no. 3, pp. 712719, 1996.

[16] L. B. Pritzker, T. A. Nguyen, and M. A. Moscarello, "The developmental expression and activity of peptidylarginine deiminase in the mouse," Neuroscience Letters, vol. 266, no. 3, pp. 161-164, 1999.

[17] Y. Wang, M. Li, S. Stadler et al., "Histone hypercitrullination mediates chromatin decondensation and neutrophil extracellular trap formation," Journal of Cell Biology, vol. 184, no. 2, pp. 205-213, 2009.

[18] R. S. Lewis, "Calcium signaling mechanisms in T lymphocytes," Annual Review of Immunology, vol. 19, pp. 497-521, 2001.

[19] M. E. Stensland, S. Pollmann, Ø. Molberg, L. M. Sollid, and B. Fleckenstein, "Primary sequence, together with other factors, influence peptide deimination by peptidylarginine deiminase4," Biological Chemistry, vol. 390, no. 2, pp. 99-107, 2009.

[20] E. R. Vossenaar, T. R. D. Radstake, A. van der Heijden et al., "Expression and activity of citrullinating peptidylarginine deiminase enzymes in monocytes and macrophages," Annals of the Rheumatic Diseases, vol. 63, no. 4, pp. 373-381, 2004.

[21] L. Klareskog, M. Widhe, M. Hermansson, and J. Ronnelid, "Antibodies to citrullinated proteins in arthritis: pathology and promise," Current Opinion in Rheumatology, vol. 20, no. 3, pp. 300305, 2008.

[22] S. Rantapää-Dahlqvist, B. A. W. de Jong, E. Berglin et al., "Antibodies against cyclic citrullinated peptide and IgA rheumatoid factor predict the development of rheumatoid arthritis," Arthritis and Rheumatism, vol. 48, no. 10, pp. 2741-2749, 2003.

[23] M. M. J. Nielen, D. van Schaardenburg, H. W. Reesink et al., "Specific autoantibodies precede the symptoms of rheumatoid arthritis: a study of serial measurements in blood donors," Arthritis and Rheumatism, vol. 50, no. 2, pp. 380-386, 2004.

[24] F. A. van Gaalen, S. P. Linn-Rasker, W. J. van Venrooij et al., "Autoantibodies to cyclic citrullinated peptides predict progression to rheumatoid arthritis in patients with undifferentiated arthritis: a prospective cohort study," Arthritis and Rheumatism, vol. 50, no. 3, pp. 709-715, 2004.

[25] A. Kastbom, G. Strandberg, A. Lindroos, and T. Skogh, "AntiCCP antibody test predicts the disease course during 3 years in early rheumatoid arthritis (the Swedish TIRA project)," Annals of the Rheumatic Diseases, vol. 63, no. 9, pp. 1085-1089, 2004.

[26] K. Ikari, M. Kuwahara, T. Nakamura et al., "Association between PADI4 and rheumatoid arthritis: a replication study," Arthritis and Rheumatism, vol. 52, no. 10, pp. 3054-3057, 2005.

[27] A. Barton, J. Bowes, S. Eyre et al., "A functional haplotype of the PADI4 gene associated with rheumatoid arthritis in a Japanese population is not associated in a United Kingdom population," Arthritis and Rheumatism, vol. 50, no. 4, pp. 1117-1121, 2004.

[28] L. Caponi, E. Petit-Teixeira, M. Sebbag et al., "A family based study shows no association between rheumatoid arthritis and 
the PADI4 gene in a white French population," Annals of the Rheumatic Diseases, vol. 64, no. 4, pp. 587-593, 2005.

[29] A. Martinez, A. Valdivia, D. Pascual-Salcedo et al., "PADI4 polymorphisms are not associated with rheumatoid arthritis in the Spanish population," Rheumatology, vol. 44, no. 10, pp. 12631266, 2005.

[30] F. C. Arnett, S. M. Edworthy, D. A. Bloch et al., "The American rheumatism association 1987 revised criteria for the classification of rheumatoid arthritis," Arthritis and Rheumatism, vol. 31, no. 3, pp. 315-324, 1988.

[31] M. L. L. Prevoo, M. A. van'T Hof, H. H. Kuper, M. A. van Leeuwen, L. B. A. van de Putte, and P. L. C. M. van Riel, "Modified disease activity scores that include twenty-eight-joint counts: development and validation in a prospective longitudinal study of patients with rheumatoid arthritis," Arthritis and Rheumatism, vol. 38, no. 1, pp. 44-48, 1995.

[32] M. H. Cardiel, M. Abello-Banfi, R. Ruiz-Mercado, and D. Alarcon-Segovia, "How to measure health status in rheumatoid arthritis in non-English speaking patients: validation of a Spanish version of the Health Assessment Questionnaire Disability Index (Spanish HAQ-DI)," Clinical and Experimental Rheumatology, vol. 11, no. 2, pp. 117-121, 1993.

[33] G. Ting, S. Schneeweiss, J. N. Katz et al., "Performance of a rheumatoid arthritis records-based index of severity," Journal of Rheumatology, vol. 32, no. 9, pp. 1679-1687, 2005.

[34] S. Gustincich, G. Manfioletti, G. Del Sal, C. Schneider, and P. Carninci, "A fast method for high-quality genomic DNA extraction from whole human blood," BioTechniques, vol. 11, no. 3, pp. 298-302, 1991.

[35] M. Stephens, N. J. Smith, and P. Donnelly, "A new statistical method for haplotype reconstruction from population data," American Journal of Human Genetics, vol. 68, pp. 978-989, 2001.

[36] A. K. Abbas and A. H. Lichtman, Basic Immunology: Functions and Disorders of the Immune System, WB Saunders, Philadelphia, Pa, USA, 2nd edition, 2004.

[37] P. Matzinger, "The danger model: a renewed sense of self," Science, vol. 296, no. 5566, pp. 301-305, 2002.

[38] K. L. Rock and H. Kono, "The inflammatory response to cell death," Annual Review of Pathology, vol. 3, pp. 99-126, 2008.

[39] H. Kono and K. L. Rock, "How dying cells alert the immune system to danger," Nature Reviews Immunology, vol. 8, no. 4, pp. 279-289, 2008.

[40] F. Martinon, K. Burns, and J. Tschopp, “The Inflammasome: a molecular platform triggering activation of inflammatory caspases and processing of proIL- $\beta$," Molecular Cell, vol. 10, no. 2, pp. 417-426, 2002.

[41] F. Martinon, A. Mayor, and J. Tschopp, "The inflammasomes: guardians of the body," Annual Review of Immunology, vol. 27, pp. 229-265, 2009.

[42] C. M. Weyand and J. J. Goronzy, "Pathogenesis of rheumatoid arthritis," Medical Clinics of North America, vol. 81, no. 1, pp. 2955, 1997.

[43] T. Iwamoto, K. Ikari, T. Nakamura et al., "Association between PADI4 and rheumatoid arthritis: a meta-analysis," Rheumatology, vol. 45, no. 7, pp. 804-807, 2006.

[44] Y. H. Lee, Y. H. Rho, S. J. Choi, J. D. Ji, and G. G. Song, "PADI4 polymorphisms and rheumatoid arthritis susceptibility: a metaanalysis," Rheumatology International, vol. 27, no. 9, pp. 827-833, 2007.

[45] C. Gorodezky, C. Alaez, M. N. Vázquez-García et al., “The genetic structure of Mexican Mestizos of different locations: tracking back their origins through MHC genes, blood group systems, and microsatellites," Human Immunology, vol. 62, no. 9, pp. 979-991, 2001.

[46] B. Hoppe, G. A. Heymann, F. Tolou, H. Kiesewetter, T. Doerner, and A. Salama, "High variability of peptidylarginine deiminase 4 (PADI4) in a healthy white population: characterization of six new variants of PADI4 exons 2-4 by a novel haplotype-specific sequencing-based approach," Journal of Molecular Medicine, vol. 82, no. 11, pp. 762-767, 2004.

[47] C. P. Kang, H.-S. Lee, H. Ju, H. Cho, C. Kang, and S.-C. Bae, "A functional haplotype of the PADI4 gene associated with increased rheumatoid arthritis susceptibility in Koreans," Arthritis and Rheumatism, vol. 54, no. 1, pp. 90-96, 2006.

[48] F. Gandjbakhch, I. Fajardy, B. Ferré et al., "A functional haplotype of PADI4 gene in rheumatoid arthritis: positive correlation in a french population," Journal of Rheumatology, vol. 36, no. 5, pp. 881-886, 2009.

[49] G. A. Schellekens, H. Visser, B. A. de Jong et al., "The diagnostic properties of rheumatoid arthritis antibodies recognizing a cyclic citrullinated peptide," Arthritis and Rheumatism, vol. 43, no. 1, pp. 155-163, 2000.

[50] M. G. Zavala-Cerna, A. Nava, E. Garcia-Castaneda, J. DuranGonzalez, M. J. Arias-Merino, and M. Salazar-Paramo, "Serum IgG activity against cyclic citrullinated peptide in patients evaluated for rheumatoid factor correlates with the IgM isotype," Rheumatology International, vol. 28, no. 9, pp. 851-857, 2008.

[51] G. Lakos, L. Soos, A. Fekete et al., "Anti-cyclic citrullinated peptide antibody isotypes in rheumatoid arthritis: association with disease duration, rheumatoid factor production and the presence of shared epitope," Clinical and Experimental Rheumatology, vol. 26, no. 2, pp. 253-260, 2008.

[52] K. N. Verpoort, C. M. Jol-van der Zijde, E. A. M. Papendrechtvan der Voort et al., "Isotype distribution of anti-cyclic citrullinated peptide antibodies in undifferentiated arthritis and rheumatoid arthritis reflects an ongoing immune response," Arthritis and Rheumatism, vol. 54, no. 12, pp. 3799-3808, 2006.

[53] D. Makrygiannakis, E. Af Klint, I. E. Lundberg et al., "Citrullination is an inflammation-dependent process," Annals of the Rheumatic Diseases, vol. 65, no. 9, pp. 1219-1222, 2006.

[54] J. A. Hill, S. Southwood, A. Sette, A. M. Jevnikar, D. A. Bell, and E. Cairns, "Cutting edge: the conversion of arginine to citrulline allows for a high-affinity peptide interaction with the rheumatoid arthritis-associated HLA-DRB1 ${ }^{*} 0401$ MHC class II molecule," Journal of Immunology, vol. 171, no. 2, pp. 538-541, 2003.

[55] R. M. Plenge, L. Padyukov, E. F. Remmers et al., "Replication of putative candidate-gene associations with rheumatoid arthritis in $>4,000$ samples from North America and Sweden: association of susceptibility with PTPN22, CTLA4, and PADI4," American Journal of Human Genetics, vol. 77, no. 6, pp. 10441060, 2005. 


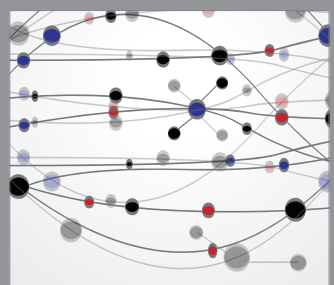

The Scientific World Journal
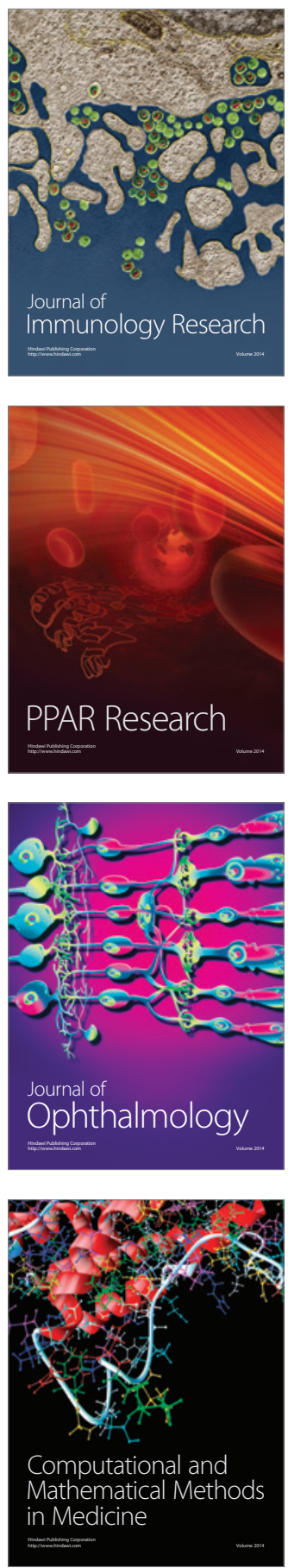

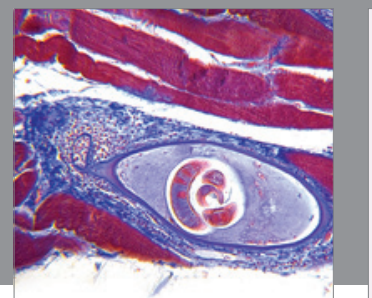

Gastroenterology

Research and Practice
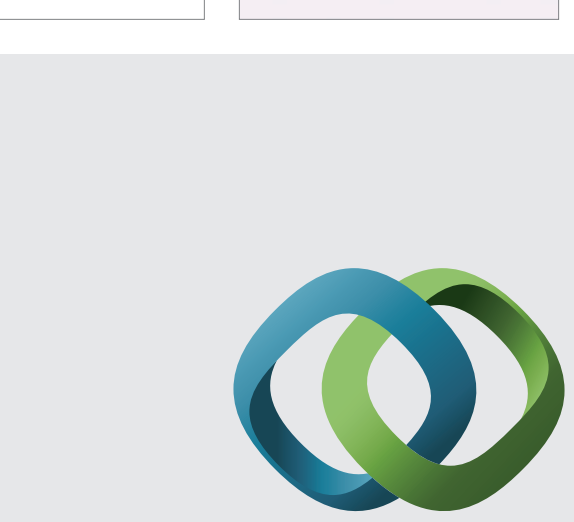

\section{Hindawi}

Submit your manuscripts at

http://www.hindawi.com
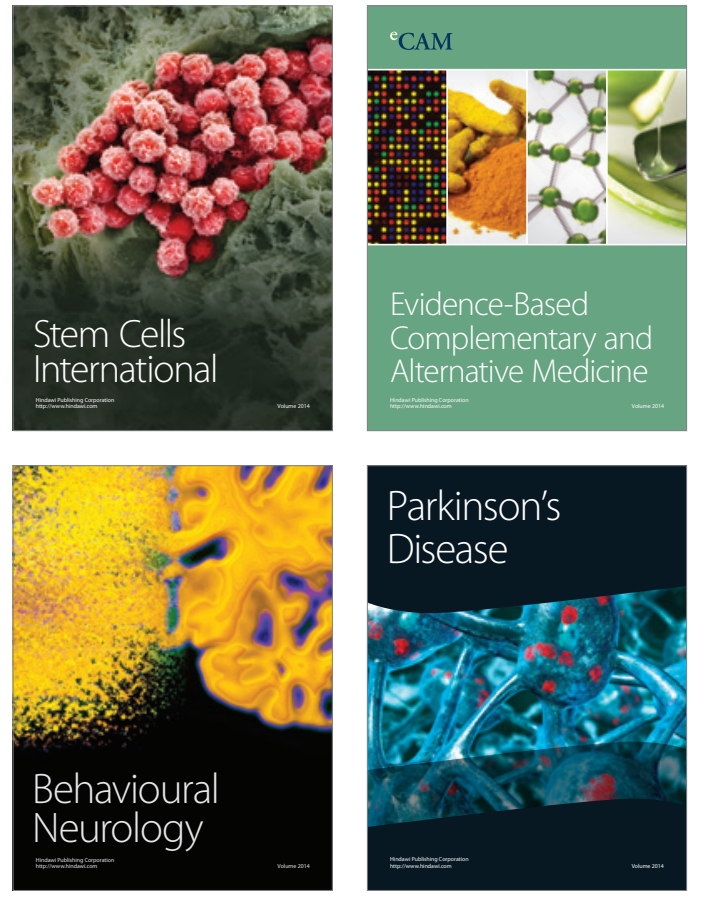
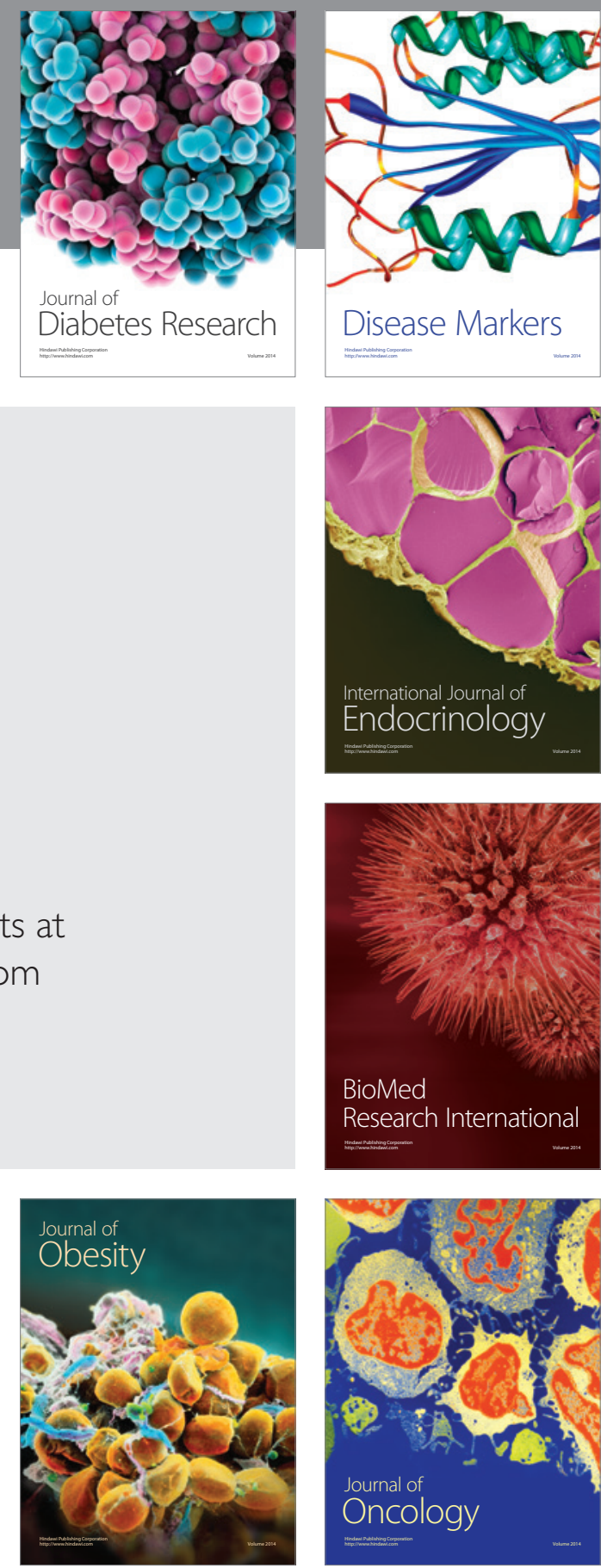

Disease Markers
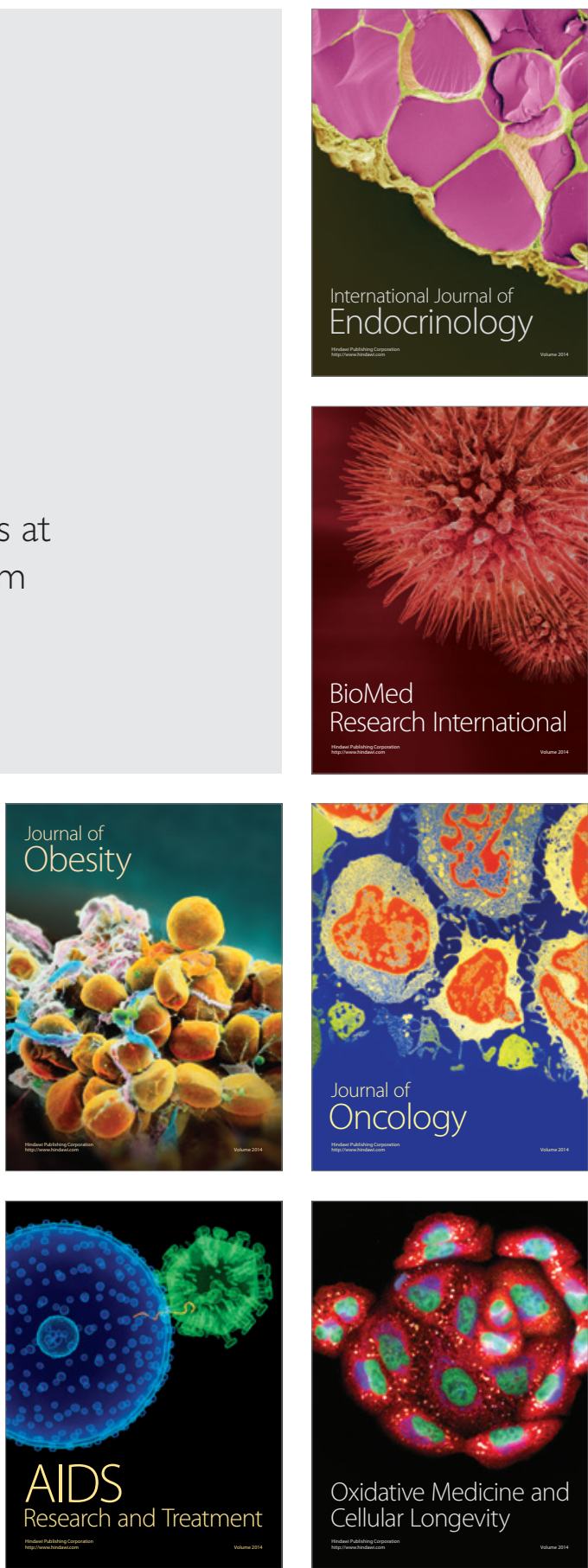